\title{
HUBUNGAN OPTIMISME MASA PERSIAPAN PENSIUN DENGAN SINDROM PURNA KUASA PADA PEGAWAI NEGERI SIPIL (PNS) GURU DI KOTA MAKASSAR
}

\section{THE RELATIONSHIP BETWEEN OPTIMISM RETIREMENT PREPARATION AND POST-POWER SYNDROME FOR TEACHERS AS CIVIL SERVANT IN MAKASSAR}

\author{
Puji Rahayu ${ }^{1}$, Widyastuti ${ }^{2}$, dan Ahmad Ridfah ${ }^{3}$ \\ ${ }^{1}$ Universitas Negeri Makassar \\ e-mail: pujirharis20@gmail.com \\ ${ }^{2}$ Universitas Negeri Makassar \\ e-mail: widya_prasthya@yahoo.com \\ ${ }^{3}$ Universitas Negeri Makassar \\ e-mail: ahmad.ridfah@unm.ac.id
}

\begin{abstract}
Abstrak
Gejala sindrom purna kuasa yang dialami oleh individu yang sudah tidak bekerja atau sudah memasuki masa persiapan pensiun sering dialami oleh Pegawai yang akan berakhir maupun telah berakhir masa kerjanya. Penelitian ini bertujuan untuk mengetahui hubungan optimisme masa persiapan pensiun dan sindrom purna kuasa. Metode Penelitian adalah kuantitaif-asosiatif. Populasi dalam penelitian ini adalah Pegawai Negeri Sipil (PNS) Guru yang ada di kota Makassar dan pengambilan sampel sebanyak 29 orang menggunakan teknik accidental sampling, mengingat penelitian ini bersifat non parametrik dimana sampel boleh berjumlah kurang dari 30 orang. Hasil penelitian menunjukkan bahwa terdapat hubungan negatif antara optimisme masa persiapan pensiun dan sindrom purna kuasa, $r=-0,822(p=0,000)$. Artinya, semakin tinggi optimisme masa persiapan pensiun maka semakin rendah sindrom purna kuasa pada Tenaga Pengajar (Guru) yang berstatus PNS. Hal tersebut menunjukkan ada pengaruh negatif yang siginifikan antara optimisme masa persiapan pensiun dan sindrom purna kuasa. Implikasi dari penelitian ini adalah sebagai informasi untuk menanamkan sikap optimisme dalam diri untuk menghadapi masa persiapan pensiun agar terhindar dari sindrom purna kuasa.
\end{abstract}

Kata kunci: Pensiun, Masa Persiapan Pensiun, Sindrom Purna Kuasa, Pegawai Negeri Sipil, dan Guru.

\begin{abstract}
The symptoms of post power syndrome are often experienced by individuals who are retired or has entered a period prior to retirement. This study aims to determine the relationship between optimism retirement preparation and post power syndrome. This study aims to determine the relationship of optimism during the preparation of retirement and post power syndrome. Research method is quantitative-associative. The population in this research is Civil Servant (PNS) of teachers in Makassar city and sampling of 29 people using accidental sampling technique, considering this research is non parametric where the sample may amount to less than 30 people. The result showed there is a negative relationship between optimism retirement preparation and
\end{abstract}


post-power syndrome, $r=-0.822(p=0.000)$. That is, the higher the optimism of retirement preparation period, the lower the syndrome of powers on the teachers as civil servants. This suggests that there is a significant negative influence between optimism of retirement preparation period and post-power syndrome. This study implicates that it is necessary to instill an optimism attitude in order to face future retirement period as an attempt to avoid the post-power syndrome.

Keywords: Retirement, Retirement Preparation, Post-Power Syndrome, Civil Servant, and Teacher.

\section{PENDAHULUAN}

Masa pensiun adalah masa dimana individu berhenti dari aktivitas bekerja secara formal yang disebabkan karena bertambahnya usia dan diikuti oleh kemunduran fisik. Indonesia memiliki kebijakan sendiri dalam hal usia pensiun guru. Menurut Pasal 40 ayat (4) UU No. 4 Tahun 2005 tentang Guru dan Dosen batas usia pensiun guru adalah 60 tahun.

Usia 60 tahun tergolong pada fase perkembangan lanjut usia. Fenomena mengenai masalah psikologis yang dialami oleh lanjut usia didukung oleh penelitian yang dilakukan Lawinsohn (Santrock, 2002). Lewinsohn mengungkapkan bahwa sekitar $80 \%$ dari individu lanjut usia menunjukkan gejalagejala depresi, 7\% dari individu lanjut usia memiliki gangguan kecemasan dan lebih parah lagi 25\% dari individu yang melakukan bunuh diri di Amerika Serikat adalah individu yang berusia lebih dari 65 tahun. Masalah mental terjadi karena ketidakmampuan individu menerima berbagai perubahan dalam hidupnya.

Murwani dkk. (2011) memaparkan bahwa pihak yang paling takut menghadapi masa pensiun adalah Pegawai Negeri Sipil (PNS). Pegawai Negeri Sipil (PNS) yang telah memasuki masa purna tugasnya atau pensiun, mengalami mental shock (faktor kejiwaan), keadaan ini terkait dengan pola pikir. Walgito (2004) memaparkan bahwa individu berpikir bila menghadapi permasalahan atau persoalan. Berpikir dilakukan agar individu bisa menemukan optimisme dalam dirinya.

Seligman (1991) memaparkan bahwa sikap optimis sebagai suatu sikap yang mengharapkan hasil yang positif dalam menghadapi masalah, dan berharap untuk mengatasi stres serta tantangan sehari-hari secara efektif. Seligman (1991) menjelaskan bahwa terbentuknya pola pikir optimis tergantung cara pandang individu pada perasaan dirinya bernilai atau tidak. Perasaan bernilai dan berarti biasanya tumbuh dari pengakuan oleh lingkungan.

Peneliti melakukan survai Pegawai Negeri Sipil (PNS), dalam hal ini Guru di kota Makassar. Survai dilakukan melalui pengamatan dan wawancara langsung. Hasil survai menunjukkan adanya fenomena-fenomena seperti: terdapat individu yang memiliki pandangan bahwa kekuasaannya masih akan dimiliki ketika pensiun nanti dan mengungkapkan seakan-akan kalau hal tersebut akan dimiliki oleh individu secara terus menerus. Hasil wawancara juga menunjukkan kekhawatiran yang begitu mendalam pada individu karena akan memasuki masa pensiun, seakan individu belum siap untuk menghadapi masa pensiun karena merasa takut akan dihindari oleh orang-orang di lingkungannya.

Chaplin (1991) menyebutkan bahwa sindrom adalah suatu kelompok atau pola gejala-gejala yang mencirikan penyakit atau kondisi tertentu, kumpulan dari peristiwa-peristiwa, tindakan-tindakan, objek-objek dan lainlain yang berhubungan. Santoso dan 
Lestari (2008) mengungkapkan bahwa sindrom purna kuasa banyak dialami oleh individu yang baru saja atau hampir memasuki waktu pensiun, dimana mereka merasa stres, depresi, tidak bahagia, dan atau merasa kehilangan harga diri serta kehormatan. Suardiman (2011) mengungkapkan bahwa kecenderungan sindrom purna kuasa merupakan ketidakmampuan individu untuk berpikir secara realistis dan menerima kenyataan bahwa individu sudah kurang mampu bekerja dengan produktif. Individu yang sangat berpotensi untuk menderita sindrom purna kuasa adalah individu yang terlalu mencintai pekerjaan dan menganggap pekerjaan sebagai satu-satuya hal yang mendatangkan status sosial dan kepuasan.

Murwani dan Priyantari (2011) membagi gejala sindrom purna kuasa ke dalam tiga tipe, yaitu: gejala fisik, gejala emosi, dan gejala perilaku. Gejala fisik terlihat dari tampilan yang tampak lebih tua, rambut semakin banyak yang memutih, berkeriput, sakit-sakitan, lemah, serta tidak bergairah. Gejala emosi terlihat dari cepat tersinggung, merasa tidak berharga, ingin menarik diri dari lingkungan, ingin bersembunyi, dls. Gejala perilaku meliputi malu bertemu individu lain, lebih mudah melakukan pola-pola kekerasan, atau menunjukkan kemarahan.

Ekasari dan Susanti (2009) mendefenisikan individu optimisme sebagai individu yang akan lebih memperkirakan atau mengantisipasi hasil ke arah yang lebih baik dibandingkan hasil yang lebih buruk ketika individu berhadapan dengan berbagai masalah dalam berbagai bidang kehidupan. Seligman (1991) menamakan cara atau gaya yang menjadi kebiasaan individu dalam menjelaskan kepada diri sendiri mengapa suatu peristiwa terjadi sebagai gaya penjelasan. Gaya penjelasan yang dipakai merupakan indikator optimis atau pesimis individu. Seligman
(1991) menyebut bahwa, gaya penjelasan individu terdiri dari tiga aspek, yaitu :

a. Permanensi,

b. Pervasivitas, dan

c. Personalisasi,

Permanensi merupakan gaya penjelasan yang berkaitan dengan waktu. Individu yang optimis akan melihat peristiwa yang tidak menyenangkan sebagai sesuatu yang terjadi secara temporer. Pervasivitas adalah gaya penjelasan yang berkaitan dengan dimensi ruang lingkup. Individu yang optimis akan menghadapi peristiwa yang tidak menyenangkan dengan cara spesifik dan melihat peristiwa yang menyenangkan sebagai sesuatu yang universal. Personalisasi merupakan gaya penjelasan yang berkaitan dengan penyebab. Individu yang optimis memandang masalah-masalah yang menekan berasal dari masalah lingkungan dan memandang peristiwa yang menyenangkan berasal dari dalam dirinya (Seligman, 1991).

Individu yang mengalami sindrom purna kuasa biasanya menganggap bahwa jabatan atau pekerjaannya merupakan hal yang sangat membanggakan bahkan cenderung menjadikan pekerjaan sebagai dunianya. Pekerjaan yang hilang karena pensiun memberikan dampak psikologis pada mental individu. Hasil penelitian sebelumnya yang dilakukan oleh Yunian (2013) dengan judul pengaruh optimisme menghadapi masa pensiun terhadap sindrom purna kuasa pada anggota badan pembina pensiunan pegawai (BP3) Pelindo Semarang mengatakan bahwa optimisme menghadapi masa pensiun pada anggota Badan Pembina Pensiunan Pegawai (BP3) Pelindo tergolong tinggi. Subjek penelitian tersebut sebanyak 63 subjek. Aspek yang paling berpengaruh pada optimisme menghadapi masa pensiun adalah aspek personalization. Hasil menunjukkan bahwa anggota Badan 
Pembina Pensiunan Pegawai (BP3) Pelindo memiliki keyakinan yang kuat bahwa hal yang baik berasal dari dirinya sendiri sedangkan yang buruk bukan berasal dari dirinya.

Individu yang bekerja akan tiba pada suatu masa, dimana individu tersebut harus berhenti dari pekerjaannya. Individu yang berhenti dari pekerjaannya dikarenakan sudah memasuki masa pensiun atau usianya sudah tidak muda lagi. Pensiun merupakan suatu keadaan dimana individu sudah tidak bekerja lagi, atau ada kesepakatan dari individu yang bersangkutan dengan instansi terkait untuk melakukan pensiun dini. Perubahan keadaan dari bekerja menjadi tidak bekerja oleh sebagian individu dianggap tidak menyenangkan. Pensiun dianggap sebagai akhir segalanya. Keadaan ini dapat menimbulkan simptom-simptom yang membuat individu akan terserang masalah kejiwaan yang disebut sindrom purna kuasa.

Individu yang menjelang pensiun mempersiapkan diri untuk memasuki masa pensiun dengan pikiran-pikiran positif, akan dapat menghindari munculnya sindrom purna kuasa. Individu dapat memandang masa pensiun dengan pikiran yang optimis dapat menikmati masa pensiun dengan tenang dan bahagia. Perubahan yang terjadi pada individu yang tadinya memiliki jabatan/bekerja lalu tidak bekerja membuat sebagian individu menganggap keadaan ini sangat tidak menyenangkan.

Optimisme akan sangat membantu individu untuk terhindar dari pikiranpikiran negatif. Melalui pikiran yang optimis, individu yang menjalani masa pensiun akan lebih tahan terhadap tekanan dan juga depresi sehingga membuat individu terlihat lebih bahagia, bahkan lebih menikmati masa dengan tenang dan lebih produktif meski sudah tidak bekerja lagi.
Berdasarkan uraian di atas, Peneliti tertarik untuk mengangkat dan mengungkap secara empiris mengenai hubungan optimisme masa persiapan pensiun dan sindrom purna kuasa, maka Peneliti mengajukan hipotesis berikut "Ada hubungan negatif antara optimisme masa persiapan pensiun dengan sindrom purna kuasa pada Pegawai Negeri Sipil (PNS) Guru di kota Makassar”. Dimana, semakin tinggi optimisme masa persiapan pensiun maka semakin rendah sindrom purna kuasa yang dimiliki oleh Pegawai Negeri Sipil (PNS) Guru, sebaliknya semakin rendah optimisme masa persiapan pensiun maka semakin tinggi sindrom purna kuasa yang dimiliki oleh Pegawai Negeri Sipil (PNS) Guru”.

\section{METODE PENELITIAN}

\section{Tipe penelitian}

Penelitian ini merupakan penelitian kuantitatif-asosiatif yang menguji hubungan antara optimisme masa persiapan pensiun dengan sindrom purna kuasa pada Pegawai Negeri Sipil (PNS) Guru di kota Makassar.

\section{Populasi dan sampel}

Populasi dalam penelitian ini adalah Pegawai Negeri Sipil (PNS) Guru yang ada di kota Makassar. Metode pengambilan sampel dalam penelitian ini menggunakan teknik accidental sampling (sampling kebetulan) yang diambil karena kebetulan ditemui. Kriteria subjek adalah individu yang berstatus sebagai Pegawai Negeri Sipil (PNS) Guru yang ada di kota Makassar dan berumur 51-58 tahun. Jumlah subjek dalam penelitian ini adalah sebanyak 29 orang.

\section{Teknik pengumpulan data}

Data dikumpulkan menggunakan skala psikologi. Skala terdiri dari pernyataan yang diajukan agar dijawab oleh Responden, dan interpretasi 
jawaban Responden dapat merupakan proyeksi dari perasaan Responden. Skala psikologi diartikan sebagai suatu prosedur pengambilan data dengan mengungkapkan konstruk psikologis yang menggambarkan aspek kepribadian dari subjek yang diteliti (Azwar, 2010). Skala psikologi yang digunakan dalam penelitian ini adalah:

a. Skala sindrom purna kuasa dalam penelitian ini di adaptasi dari Umniyah Saleh (2005).

b. Skala optimisme dalam penelitian ini disusun berdasarkan teori Seligman (1991).

Validitas alat ukur yang digunakan dalam penelitian ini adalah validitas isi. Validitas isi merupakan validitas yang diestimasi melalui pengujian terhadap isi tes dengan analisis rasional atau melalui profesional judgment (Azwar, 2013). Azwar (2013) menyebutkan bahwa penilaian ahli (professional judgment) dapat berjumlah 3 orang. Berdasarkan hasil Aiken-v, seluruh item dinyatakan relevan dan siap untuk diuji coba kepada subek penelitian. Nilai yang diperoleh untuk validasi item bergerak dari 0,5831,00. Uji coba dilakukan pada Tenaga Pengajar yang berada di kota Makassar. Subjek uji coba berstatus sebagai Pegawai Negeri Sipil (PNS) Guru dan berjumlah 108 orang.

Korelasi item total digunakan untuk analisis item sebagai bagian awal dalam menyeleksi aitem-item yang layak digunakan dalam tes secara keseluruhan. Menurut Azwar (2012) sebagai kriteria pemilihan item berdasarkan korelasi item total, biasanya digunakan batasan koefisien $>0,30$. Setelah uji coba, tersisa 34 item skala optimism yang dapat digunakan dalam penelitian, sedangkan skala sindrom purna kuasa memiliki 27 item.

Berdasarkan hasil uji coba, koefisien reliabilitas skala optimisme memperoleh nilai alpha sebesar 0,916 dan koefisien reliabilitas skala sindrom purna kuasa adalah sebesar 0,926. Kedua skala dalam penelitian ini dianggap memuaskan, karena semakin koefisien reliabilitas mendekati nilai 1,00, maka semakin tinggi reliabilitasnya.

\section{Teknik analisis data}

Teknik analisis data yang digunakan adalah analisis deskriptif dan uji hipotesis. Analisis data yang digunakan untuk melihat hubungan antara optimisme dan sindrom purna kuasa adalah dengan menggunakan teknik korelasi Spearman yang perhitungannya dilakukan dengan bantuan program SPSS 21.0 for windows.

\section{HASIL}

Variabel X dalam penelitian ini adalah sindrom purna kuasa. Sindrom purna kuasa adalah keadaan yang dialami oleh individu yang telah purna, tidak bekerja atau menganggur yang ditandai dengan beberapa aspek yaitu : gejala fisik, psikis, dan gejala perilaku. Variabel Y dalam penelitian ini adalah optimisme masa persiapan pensiun. Optimisme masa persiapan pensiun merupakan suatu keyakinan pada individu yang telah mengalami pemutusan hubungan kerja. Variabel optimisme akan diukur dengan menggunakan skala optimisme yang terdiri atas aspek permanensi, aspek pervasivitas, aspek personalisasi. Skala ini dibuat oleh peneliti dengan berdasar pada teori Seligman (1991). Deskripsi data penelitian ini diperoleh berdasarkan kategorisasi variabel dengan menggunakan dua macam kategori variabel penelitian yaitu kategorisasi berdasarkan mean hipotetik dan mean empirik.

Deskripsi data optimisme disajikan dengan menggunakan rerata empirik dan standar deviasi empirik yang diperoleh dari respon jawaban subjek terhadap skala yang diberikan. Respon jawaban terendah dan tertinggi dalam skala optimisme adalah 1-5 dengan jumlah 
item sebanyak 32, skor terendah adalah 32 dan tertinggi adalah 160. Berdasarkan analisis data empirik pada variabel optimisme subjek dalam penelitian ini diperoleh hasil bahwa subjek berada pada kategori tinggi.

Deskripsi data sindrom purna kuasa disajikan dengan menggunakan rerata empirik dan standar deviasi empirik yang diperoleh dari respon jawaban subjek terhadap skala yang diberikan. Respon jawaban terendah dan tertinggi dalam skala sindrom purna kuasa adalah 1-5 dengan jumlah item sebanyak 27. Kemungkinan skor terendah adalah 27 dan tertinggi adalah 135. Berdasarkan analisis data empirik pada variabel sindrom purna kuasa subjek dalam penelitian ini diperoleh hasil bahwa subjek berada pada kategori rendah sebesar 93,1\%.

Pengujian hipotesis pada penelitian ini menggunakan analisis spearman dengan bantuan program SPSS 21.0 for Windows. Hasil analisis data optimisme dan sindrom purna kuasa diperoleh nilai $r=-0,822$ dengan $p=0,000(p<0,05)$. Dari hasil ini menunjukkan bahwa hipotesis yang menyatakan semakin tinggi optimisme masa persiapan pensiun maka semakin rendah sindrom purna kuasa sehingga dapat dikatakan hipotesis diterima.

Hasil analisis hipotesis antara optimisme masa persiapan pensiun dan sindrom purna kuasa menunjukkan bahwa sebagian besar Pegawai Negeri Sipil (Guru) di kota Makassar memiliki tingkat optimisme yang tinggi. Goleman (Nurtjahjanti \& Ratnaningsih: 2011) mengatakan bahwa Individu yang memiliki sikap optimisme memiliki harapan kuat terhadap segala sesuatu yang terdapat dalam kehidupan akan mampu teratasi dengan baik, walaupun ditimpa banyak masalah dan frustasi. Optimisme dalam jangka panjang juga bermanfaat bagi kesejahteraan dan kesehatan fisik dan mental, karena membuat individu lebih dapat menyesuaikan diri dalam kehidupan sosial, mengurangi masalah-masalah psikologis dan lebih dapat menikmati kepuasan hidup serta merasa bahagia.

Optimisme disini diukur menggunakan skala optimisme. Secara umum optimisme masa persiapan pensiun berada pada kriteria tinggi sebesar $83 \%$ dan yang berada pada kriteria sedang sebesar $17 \%$. Artinya bahwa optimisme masa persiapan pensiun termasuk pada kategori tinggi. Optimisme yang tinggi dapat menangkal pemikiran negatif yang timbul, karena individu yang optimis biasanya jarang menderita depresi, selalu pantang menyerah dalam menghadapi segala masalah, menjalani kehidupan dengan perasaan bahagia, dan dapat mengendalikan emosi yang dimilikinya. Individu yang optimis dapat menikmati dan menjalani kehidupannya setelah pensiun dengan perasaan tenang dan bahagia.

Hasil yang diperoleh Peneliti, subjek memiliki nilai tinggi pada item 1 , yaitu mengukur harapan sebesar 89,65\%. Pratikto (2014) memaparkan bahwa optimisme adalah suatu keyakinan bahwa masa-masa sulit atau buruk hanya bersifat sementara dan selalu memiliki harapan bahwa sesuatu yang baik akan terjadi. Optimisme dibutuhkan dalam diri lansia agar dapat menghadapi kehidupan yang akan datang dengan keyakinan diri yang penuh dan mampu mengatasi tantangan tanpa rasa cemas dalam diri. Salah satu dimensi optimisme yaitu harapan, harapan untuk masa depan diperoleh dari pandangan individu terhadap penyebab kejadian masa lalu.

Hasil yang diperoleh Peneliti pada item 7 yang berfungsi untuk mengukur semangat subjek untuk berkembang adalah 89,65\%. Nurtjahjanti dan Ratnaningsih (2011) keberhasilan individu di masa depan akan diperoleh bila individu memiliki optimisme yang ditandai dengan semangat yang tinggi 
dalam mewujudkan masa depan yang lebih baik. individu yang memiliki pola pikir optimis dalam hidupnya akan memiliki kepercayaan diri dalam melaksanakan pekerjaannya sehari-hari, mereka juga cenderung lebih berbahagia dalam menjalani kehidupan.

\section{PEMBAHASAN}

Sindrom purna kuasa merupakan reaksi somatis berupa sekumpulan symptom-symptom atau gejala berupa penyakit ataupun kerusakan pada tubuh baik jasmani ataupun rohani yang bersifat progresif yang biasanya terjadi pada individu yang tidak bekerja atau tidak menjabat lagi. Biasanya sindrom purna kuasa ini terjadi karena individu menganggap bahwa pekerjaan dan bekerja itu sebagai kebutuhan dasar, dan merupakan bagian penting dari kehidupan manusia. Hal ini disebabkan bekerja memberikan kesenangan dan arti tersendiri bagi kehidupan manusia seperti memberikan ganjaran berupa material seperti gaji dan macam macam fasilitas material lainnya, dan juga ganjaran sosial seperti status sosial, respek dan prestige sosial. Sebaliknya tidak bekerja, menganggur atau pensiun dialami sebagai suatu shock dan dianggap sebagai kerugian yang menimbulkan perasaan perasaan negatif. Sebenarnya yang menjadi kriterium utama bukanlah kondisi atau situasi pensiun, melainkan bagaimana caranya individu menghayati dan menerima keadaan pensiun tersebut (Semiun, 2010).

Secara umum sindrom purna kuasa yang dialami oleh Pegawai Negeri Sipil (Guru) berada pada kriteria rendah, apabila sindrom purna kuasa tergolong rendah hal ini menandakan bahwa Pegawai Negeri Sipil tersebut dapat menghayati dan atau merasakan keadaan baru nantinya sebagai individu pensiunan dengan perasaan lega, puas, bahagia karena sudah melakukan semua tugas atau kewajiban kelembagaannya dengan upaya semaksimal mungkin, sehingga individu tersebut bisa merasakan kelegaan dan kebebasan. Perasaan rela, ikhlas, lega dan bahagia menerima keadaan baru tersebut dapat mengurangi perasaan perasaan negatif akibat sindrom purna kuasa.

Item nomor 26 yang diukur oleh peneliti menunjukkan skor adalah $30,37 \%$ yang menandakan hanya sebagian subjek yang mengalami sindrom purna kuasa dengan ditandai suka melamun. Pada item nomor 7 skor yang diperoleh adalah dari kelompok subjek adalah 34,07\% yang menandakan rendah pada perasaan kehilangan harga diri. Sebagian orang dalam menghadapi masa pensiun memiliki pandangan positif, namun ada sebagian yang mempersepsikan pensiun secara negatif. dengan beranggapan bahwa pensiun merupakan akhir dari segalanya, individu akan memiliki kondisi mental tidak stabil, rasa kurang percaya diri, berlebih-lebihan dalam bekerja dengan anggapan bahwa individu yang pensiun tidak berguna lagi serta merasa tidak dibutuhkan lagi karena usia sudah tua dan produktivitas menurun. Masa pensiun bagi sebagian orang dipandang sebagai pertanda diri sudah tidak berguna sehingga menyebabkan orang menjadi sensitif, subjektif dan kurang realistis dalam menghadapi pensiun. Hal ini mengakibatkan depresi dan sindrom purna kuasa (Indriana, 2012).

Santoso dan Lestari (2008) meneliti tentang peran serta keluarga pada lansia yang mengalami sindrom purna kuasa hasil yang diperoleh adalah individu yang terkena sindrom purna kuasa mengalami persepsi negatif mengakibatkan lansia mengalami ketergantungan dan pesimis terhadap diri sendiri dalam menjalani masa tuanya. Sehingga dibutuhkan optimisme dalam menghadapi masa pensiun.

Berdasarkan hasil penelitian menunjukkan bahwa ada korelasi negatif 
yang signifikan antara optimisme masa persiapan pensiun dan sindrom purna kuasa pada pegawai negeri sipil (guru), diperoleh hasil koefisien korelasi $\mathrm{r}$ sebesar $-0,822$ dengan $p=0,000$. Hal ini menunjukkan bahwa hipotesis kerja yang diajukan diterima yaitu, ada korelasi negatif antara optimisme masa persiapan pensiun dan sindrom purna kuasa pada pegawai negeri sipil (guru) di kota Makassar. Berdasarkan hasil perhitungan di atas diketahui bahwa optimisme sangat berperan menentukan tinggi rendahnya sindrom purna kuasa. Yunian (2013) memaparkan bahwa individu yang memasuki masa pensiun sering dianggap sebagai individu yang tuna karya (tidak dibutuhkan lagi tenaga dan pikirannya). Anggapan semacam ini membuat individu tidak bisa lagi menikmati masa pensiunnya dengan hidup santai dan ikhlas. Ketakutan menghadapi masa pensiun, membuat banyak individu mengalami problem serius baik dari sisi kejiwaan maupun fisik, terlebih individu yang memiliki ambisi yang besar serta sangat menginginkan posisi yang tinggi dalam pekerjaannya. Memasuki tahapan tanpa kerja itu akan dirasakan sebagai pukulan batin. Memunculkan perasaaan sedih, takut, cemas, putus asa, bingung, yang semuanya jelas mengganggu fungsifungsi kejiwaan dan organiknya. Gejalagejala itu semua jika muncul pada individu yang telah pensiun akan mengakibatkan dirinya menderita sindrom purna kuasa. Oleh karena itu, optimisme dalam masa persiapan pensiun sangatlah penting. Menurut Yunian (2013) mengatakan bahwa optimisme menghadapi masa persiapan pensiun adalah keyakinan yang dimiliki individu dalam memandang masa pensiun dimana segala sesuatunya akan menuju kebaikan, pensiun tersebut tidak akan memengaruhi kehidupan individu yang bersangkutan sehingga di masa yang akan datang individu akan tetap berhasil.

Individu yang optimis cenderung lebih tahan terhadap depresi dan mampu menyeimbangkan emosinya. Individu yang memiliki optimisme yang tinggi mengindikasikan mampu menerima keadaan barunya dan mengontrol emosiemosi negatif yang muncul yang bisa menyebabkan sindrom purna kuasa. Kenaikan suatu variabel mengakibatkan penurunan variabel yang lainnya, semakin tinggi optimisme masa persiapan pensiun semakin rendah sindrom purna kuasa pada pegawai negeri sipil (guru), hal ini juga berlaku sebaliknya.

\section{KESIMPULAN DAN SARAN}

Kami menyimpulkan bahwa terdapat hubungan negatif antara optimisme masa persiapan pensiun dan sindrom purna kuasa. Nilai $r=-0,822$ menunjukkan bahwa makin besar optimisme individu, maka kecenderungan untuk mengalami sindrom purna kuasa juga semakin rendah. Oleh karena itu, tenaga pengajar diharapkan tetap memiliki optimisme tinggi, optimisme tersebut sangat berguna dalam menanggulangi pengaruh dari sindrom purna kuasa. Memiliki optimisme yang tinggi dapat menjalani masa pensiun dengan tenang dan bahagia. Di samping itu, pihak instansi tetap memberikan kegiatan yang positif yang dapat mempertahankan rasa optimisme bagi PNS yang akan memasuki masa pensiun. Kegiatan keagamaan dapat dijadikan pilihan agar dapat menjadi pengisi waktu luang serta motivasi dan semangat. 


\section{REFERENSI}

Azwar, Saifuddin. 2013. Dasar-dasar Psikometri. Yogyakarta: Pustaka Pelajar.

Azwar, Saifuddin. 2012. Penyusunan Skala Psikologi. Yogyakarta: Pustaka Pelajar.

Azwar, Saifuddin. 2010. Metode Penelitian. Yogyakarta: Pustaka Pelajar.

Azwar, Saifuddin. 2006. Penyusunan Skala Psikologi. Yogyakarta: Pustaka Pelajar.

Chaplin, James Patrick. 1991. Kamus Lengkap Psikologi (Diterjemahkan oleh Kartini Kartono). Jakarta: PT. RajaGrafindo Persada.

Creswell, John W. 2012. Educational Research: Planning, Conducting, and Evaluating Quantitative and Qualitative Research ( $4^{\text {th }}$ ed). Boston: Pearson.

Ekasari, Agustina A dan Agustina. 2009. Hubungan antara Optimisme dan Penyesuaian Diri dengan Stres pada Narapidana Kasus Napza di Lapas Kelas IIA Bulak Kapal Bekasi. Jurnal FISIP: Soul, (2).

Hadi, Sutrisno. 2009. Statistik jilid 2. Yogyakarta: Andi.

Indriana, Yeniar. 2012. Gerontologi dan Progeria. Yogyakarta: Pustaka Pelajar.

Murwani, Arita dan Priyantari, Wiwin. 2011. Gerontik. Yogyakarta: Fitramaya.

Nurtjahjanti, Harlina dan Ratnaningsih, Ika Zenita. 2011. Hubungan Kepribadian Hardiness dengan Optimisme pada Calon Tenaga Kerja Indonesia (CTKI) Wanita di BLKLN Disnakertrans Jawa Tengah. Jurnal Psikologi Undip, 2(10).
Pratikto, Novia Margareta. 2014. Optimisme pada Lansia Ditinjau dari Status Pekerjaan. Jurnal Ilmiah Mahasiswa Universias Surabaya, 3(2).

Saleh, Umniyah. 2005. Hubungan antara Penerimaan Diri dan Kecenderungan Sindrom Purna Kuasa pada Pensiunan PNS di kota Makassar. Skripsi tidak diterbitkan. Makassar: Fakultas Psikologi Universitas Makassar.

Santoso, A. \& Lestari, N. B. 2008. Peran serta Keluarga pada Lansia yang Mengalami Post Power Syndrome. Media Ners, 2(1), 1-44.

Santrock, John W. 2002. Life Span Development: Perkembangan Masa Hidup. Jakarta: Erlangga.

Seligman, Martin E. P. 1991. Learned optimism. New York: Alfred A. Knopf.

Suardiman, S. P. 2011. Psikologi Lanjut Usia. Yogyakarta: Gadjah Mada University Press.

Sugiyono. 2013. Metode Penelitian Kuantitatif, Kualitatif dan $R \& D$. Bandung: Alfabeta.

Walgito, Bimo. 2004. Pengantar Psikologi Umum. Yogyakarta: Adi.

Yunian, Fandy Achmad. 2013. Pengaruh Optimisme menghadapi Masa Pensiun terhadap Post Power Syndrome pada Anggota Badan Pembina Pensiunan Pegawai (Bp3) Pelindo Semarang. Development and Clinical psychology, ISSN 2252-6358. 